\title{
Creating Magic on Mobile
}

\author{
Martha Henson \\ Freelance \\ London \\ martha henson@yahoo.co.uk
}

\author{
Alex Butterworth \\ Amblr \\ Oxford \\ alex@amblr.net
}

\author{
Danny Birchall \\ Wellcome Collection \\ London \\ d.birchall@yahoo.co.uk
}

The cultural heritage sector has too often focussed on the delivery of greater amounts of information via mobile, rather than using the affordances of the technology and stories behind the content to create rich experiences. This paper will look at a project that attempted to go beyond the usual gallery guide and break out of the museum itself to create an innovative, playful and even magical experience on mobile.

Magic in Modern London was conceived by Amblr and Wellcome Collection, and inspired by an exhibition that brought together five hundred amulets originally collected by Edward Lovett in London at the beginning of the Twentieth century. The exhibition itself, by Felicity Powell, was an artistic interpretation of and reaction to the amulets themselves, but those amulets also suggested a different approach. Since Edward Lovett had recorded stories about many of them in his book, Magic in Modern London, they also had both narrative and location. This indicated a project that would resite the amulets and their stories back into their original place of collection, and the natural platform to achieve this was on mobile, using GPS.

The app, for iOS, is essentially a tour of Edwardian London, with geo-located audiovisual content. It starts with the beginnings of a story, narrated by "Edward Lovett" himself, as played by acclaimed actor Michael Maloney. Users are invited by Lovett to piece back together his collection, by visiting the sites where the amulets were collected. They are presented with a beautiful 1908 map overlaid onto the streets of modern London, and over a hundred "areas of enchantment" distributed across the city, each of which contain an amulet and a story. Visiting these areas triggers an immersive experience, using archive imagery, scripted narration, music and period sound recordings to create an atmospheric evocation of London of that time. On finding the amulet, they unlock a reading of Lovett's story and so piece together the book, Magic in Modern London. A 'collector's case' stores each of the sixty-four amulets as they are accumulated, from where the user can review the readings and text of the story, along with the associated images can be revisited, on returning home from their expeditions.

This paper examines this project, and others like it, to discuss the potential for creating immersive narrative experiences on mobile and the ways in which the great wealth of story, objects and imagery in museums and collections could be brought to life in this way. It will engage with issues around the responsible "fictionalising" of elements around a factual core; how light touch augmented reality (eg locative audio) can powerfully inflect the experience of place, and the delicate balance in such a project between narrative and ludic expectations.

Mobile. Audiovisual. Geolocation. Locative. History. Folklore. Edwardian London.

\section{INTRODUCTION}

The steady rise in usage and capability of smart phones presents opportunities to create engaging experiences on mobile devices. Such devices can record and play back high quality video and audio, connect you to others all over the world, afford access to inconceivable amounts of information, know where you are and show you where to go, and more. There is great potential for to use these features in any number of combinations to enchant and transport audiences, and make them look afresh at the world around them.
To date, museums have explored a number of interesting approaches. The Magic Tate Ball app suggests an artwork from the Tate's collection based on a user's immediate circumstances. It draws in temporal and environmental data collected by the phone, such as date and time, ambient sound levels and weather details, to choose something appropriate. The Streetmuseum app from the Museum of London uses GPS to overlay the view through the camera with historical images of the same place. Both of these have been very successful, suggesting that there is a genuine 
public appetite for projects such as these, while more and more museums are venturing into the area.

Unfortunately, the majority of mobile projects from the cultural heritage sector play it safe, with the audio guide as the default point of reference. Access may be provided to additional information, even via a mobile interface to the online collection, but this is most often instrumental and user directed: a jabbing at the screen to 'find out more'. The opportunity to invite the user into a more fluid and imaginative engagement with place remains largely untapped.

This paper surveys a collaborative experiment between Wellcome Collection and Amblr, a digital agency focused on the narrative interpretation of culture, to do something slightly different and quite ambitious. Conceived initially, for a niche audience, Magic In Modern London set out to explore how the lost folklore of early twentieth-century London might be evoked through geo-located sound and image, in a form that combined story and game.

It was completed and released in December 2012 for iPhone only (developing for other platforms being beyond the scope and budget of the project).

\section{THE ORIGINS OF MAGIC IN MODERN LONDON}

The project has its roots in two distinct Wellcome initiatives. One was an exhibition, Miracles and Charms, held during the winter of 2011/12. The other was a Crossover Lab focusing on the theme of collections and archives that took place in January 2011 at the invitation of the Wellcome Collection.

The purpose of the lab was to bring together curators and archivists with professionals from diverse creative disciplines to explore new ways that digital media might be used to illuminate museum collections. All three authors of this paper participated in the lab, working together over the period of a week to develop innovative ideas. During this time a shared interest emerged in telling stories with archival material.

As one part of Miracles and Charms the artist Felicity Powell brought together five hundred amulets originally collected by Edward Lovett in London at the beginning of the twentieth century for use in an original artwork with the title Charmed Life that was an artistic interpretation of and reaction to the amulets themselves. Once part of Henry Wellcome's vast collection, it had later become part of the Pitt Rivers Museum collection in
Oxford and before this exhibition had not been on display for some time.

The amulets themselves held many different stories too, many of which Lovett had recorded in his short, anecdotal book of 1925, Magic in Modern London, along in some cases with details of the location at which they were found. Additionally, Lovett himself had an intriguing biography: a chief bank cashier by day, a seeker of amulets among the hawker class of London by night, whose interest in protective magic was shadowed by the fear of disease and the horrors of the First World War.

The combination of a fascinating human story, a wealth of intriguing objects, a rich historical context and an appealing source text all suggested the subject's suitability for a digital treatment to Danny Birchall and Martha Henson, the website editor and multimedia producer at Wellcome Collection.

The subject also fitted well with the focus and interests of Amblr, a company formed by author/historian Alex Butterworth and technologists Joe Zuntz and Stuart Lynn that was in the process of testing a new geo-location platform for storytelling with a range of creative collaborators. Familiar with Alex's approach from the Crossover Lab, Amblr was invited to propose a response to a loose brief.

\section{THE PURPOSE OF THE PROJECT}

As an experimental project, Magic in Modern London was intended to test a number of propositions. At its heart was the aim of prompting users to reflect on their own attitude towards and susceptibility to superstition in twenty-first century 'modern London'. At the same time, the geolocative aspect would also encourage users to look at their environment anew, with a heightened awareness of its historical layering, with particular reference to medical history.

Experientially then, the aim was to both defamiliarise and re-enchant the everyday city in which users lived, over an extended period. Practically, this was to be achieved by insinuating the amulets, their stories and that of Lovett into users' lives via their smart phones. Two modes of engagement were to be explored, one of which would invite a brief deviation from routine, while the other would support a more sustained and planned excursion by the user.

The project would stand as a virtual legacy to the original exhibition, perpetuating the questions it posed and celebrating the memory of a marginal and largely overlooked cultural figure. 


\section{THE ORIGINAL PROPOSAL}

Certain features of the project were agreed upon from the outset and remained reasonably consistent throughout the long development process. These included:

- A central narrative conceit, based on Lovett's complaints of his treatment by certain institutions, that his beloved collection of amulets had been dispersed and that he needed help to reassemble them.

- The identification of the user with this helper, who has been provided with a map marked with 'areas of enchantment' where the amulets may be found and a collector's case into which to place them.

- The construction of these 'nodes' as layered soundscapes within which the user must navigate to the amulet's specific location, encountering cryptic clues and solutions along the way.

- A reward for success in the form of a 'virtual' amulet that released a reading of the relevant anecdotal account from Lovett's book.

Other aspects of the project were closely interrogated during the development of the design. Most crucial among these, and with the greatest impact, were the balance between recording history/autobiography and fiction, and the media used to articulate the stories. The process by which these were resolved and the implication for the interaction design will be discussed below, following a description of the app as finally realised.

\section{THE USER EXPERIENCE}

\subsection{Direct interaction}

A key challenge was translating such a complicated idea into a workable user interface in a way that tells the story, but also makes it clear what the user must do.

The basic structure of the app was a sequence of introductory screens, including an appeal by 'Edward Lovett' himself, as played by acclaimed actor Michael Maloney (who elsewhere narrates and reads the text of the original book). The last of these screens is an explanatory text that can be returned to at any time. This is followed by three navigable modes/areas of interaction: Map, Case and Notes. When in any of these areas, two buttons at the bottom of the screen allowed access to either of the other areas.

The Map: A high resolution, scanned and tiled image of a contemporary map of 1906 from the Bartholemew's Atlas of London, overlaid onto
Google Maps. At the top of the screen a slider allows the disorientated user to cross-fade between modern and historical maps. In the bottom right corner a small button centres the map on the users current location. Coloured circles indicate 'areas of enchantment' (Figure 2).

Notes: A list offering instructions, credits, the ability to tweet notification of your finds or to complete a survey (Figure 3).

Case: A collector's case composed of four trays, each with sixteen compartments in a four-by-four arrangement, that slide left to right across the screen either by finger swipe or by selecting one of the labels ' $A$ ', ' $B$ ', ' $C$ ' or ' $D$ ' that illuminate for the currently selected tray. Once collected, virtual amulets are placed in the tray. When touched, empty compartments reveal a question mark and the name of the missing amulet. When a compartment containing an amulet is touched, all information associated with that amulet, including readings and the images from the AV sequence, is revealed and can be reviewed (Figure 4).

\section{2 'Area of enchantment' interaction}

On approaching an 'area of enchantment' an audio and text alert invites further participation (even when the app is running in background mode), thus serving to nudge even those involved in their daily tasks to consider the possibility of a detour into an imaginative engagement. If the invitation is accepted, the user begins a multi-stage experience that will only finish either on completion or on their intentional departure from the 'area'.

(i) A layered soundscape becomes active that is best experienced through headphones (as the user is warned on originally launching the app).

(ii) On crossing a first boundary towards their objective, the user is offered a clue in the form of an archival image and text/voiceover (read by an actress cast as the 'Voice of all Fears'). This indicates the nature of the fear that the amulet in question will guard against, and thus hints at the precise location where it might be found.

(iii) Further changes in the soundscape occur in response to user movement, guiding it, until the location of the hidden amulet is reached, when the Voice of All Fears, accompanied by an archival image, resolves the clue with an allusive explanation.

(iv) At this point the reward sequence is initiated in the form of a reading of the relevant chapter of Lovett's book, edited for concision, accompanied by a sequence of archival images, over which 'rostrum camera' moves occur to focus narrative attention. 
(v) On completion, an image of the amulet in question appears and a request 'Send to Lovett'; when accepted, the amulet crossfades to an ink drawing, the voice of Lovett is heard offering thanks, and the amulet is placed in the collectors case.

The user can now begin their search for the next amulet.

\section{GRAPHIC DESIGN}

Relatively early in the research process, though only after many attempts had been made to acquire rights to digitised maps of the period, the map from Bartholemew's Atlas of London of 1906 was settled upon for its entrancing, rich colours. At this point, after other presentational options were considered, a decision was taken to opt for an 'antique' interface design, employing skeuomorphic elements and a colour palette consistent with the map (Figure 6).

Although the sample designs by lead designer Luis Olmos were persuasive, the decision was not simply aesthetic; more important was the question of how to engage the user in an 'immersive' story world. This was carefully weighed in light of the imperative that the user should feel him or herself inhabiting a space between that of Lovett and their own time, with the smart phone both a modern device and the gateway to a past time.

Consistent with this, the app opens with a faked, gilt and cloth book cover for Magic In Modern London (the real thing being considerably more drab) (Figure 1). The indication on the map of 'areas of enchantment' offered another design challenge: originally tinted a bruised blue (in allusion to Booth's poverty maps) it was later deemed necessary to adopt a more visible pink tinge.

\section{CHALLENGES}

\subsection{The Map}

Following our failure to secure rights to any suitable pre-digitised map and the choice of the Bartholemew's Map, in book form, considerable time and effort was required to make the map useable. The book was scanned and cropped and a browser app created to allow multi-point registration against Google Maps, with the process crowdsourced. Unfortunately, the 1908 map had not been surveyed to the same standards as Google Maps, and it was therefore not a case of just putting one over the other. Even with a large degree of manual stretching and moving around, there were still gaps. The process was twice repeated but, in the end, the solution came from Luis Olmos, who suggested that we make the gaps a feature, distressing the graphics to create the appearance an old map with bits missing and rough edges.

The crowdsourcing process that we undertook on a small scale has since been reproduced by the British Library for seven hundred maps, with a huge response. It is to be hoped that these registered maps will be made openly available, in which case the creation of apps such as this will be greatly simplified.

\subsection{The media used}

It had always been the intention that the experience of the 'areas of enchantment' should be primarily auditory. For this purpose, the composers Daniel Williams and Chris Wood each prepared multiple series of audio clips, categories according to 'fear type' that were both tractable to non-sequenced combination and could be looped. In some cases, these incorporated elements of sampled archival sound to create a further evocation of the early twentienth century. The final soundscapes were compelling, though an initial period of adjustment was required in composing for a combinatorial form.

By contrast, the original intention had been to script dramatic sequences based on the anecdotal accounts of Lovett. It was quickly decided, however, that this would be not only prohibitively expensive but would also strike the wrong register for an experienced intended to immerse the user in a historical world. Furthermore, it was our view that video in this context creates a more passive relationship between the user and screen.

Rostrum sequences using archival images were deemed both more consistent and as exercising a softer demand on the users' attention, at a delicate moment when they might still be productively preoccupied with the transformative interplay between the anecdotal narrative and the place in which they found themselves. Amblr's experience with this project, and audio-only projects such as Hackney Hear and S-Dresden have revealed both the power of light-touch audio AR and how easily the spell can be broken by the requirement for inappropriate visual and screen-based interaction.

Interpolated to the archival sequences were occasional shots of Lovett himself, as impersonated by Stephen Hancock and photographed by Alex Hocking in a variety of Edwardian settings, as if caught in the midst of a amulet-seeking excursion (Figure 5). 
The approach here was, in certain respects, inspired by the innovative 1999 film Wisconsin Death Trip and its balance of readings from insane asylum records and local newspapers voiced in character, artfully filmed vignettes of the stories recounted, and archival images. What creates unusual, poised drama-documentary offers a striking model for emergent locative forms.

\subsection{The ethics of fictionalisation}

Whilst all producers were in agreement that considerable license could be allowed in fictionalising elements of Lovett's story to create a compelling and coherent narrative, Wellcome Collection were rightly concerned both that where this occurred it should be signalled, and that beneath everything the true provenance of objects should be clearly presented.

The original plan had been for a more heavily scripted 'setting' for the anecdotal material, to draw out the underlying themes and offer some contextualising historical and biographical detail. In fact, however, in working with the existing text it became apparent that by careful selection and editing a greater effect could be achieved by allusion.

Indeed, Lovett's Magic In Modern London, offered many important insights into the best features of text for use in a characterised geolocative 'story': a strongly personalised voice, a consistent sensibility, a unity of subject, and humour. Through the superb acting of Michael Maloney, more than anything, Lovett and his world came to life and the user was taken into his mindset.

In the end, only one piece of text was scripted/fictionalised and, in this case, it was not signalled. This was a pastiche account of zeppelin raids, written in Lovett's quite imitable manner, to accompany a zeppelin amulet, in order both to accentuate the sense of wartime and allow the use of zeppelin bomb sites as 'areas'.

Certain subjects, of course, might well raise greater ethical concerns, as might projects that attempt a fuller meshing of fact and fiction, for example around objects in collections. Both are issue that Amblr is currently addressing in other projects through the use of inflections of screen-based interface design to indicate the register/reliability of audio material. More interestingly, it is also investigating how far the user can be actively engaged in piloting a narrative course between truth and falsehood to enforce ethical awareness.

\subsection{The selection of material}

In deciding to use archival images to illustrate the highly esoteric stories told by Lovett, with a minimum of three images required for each of the sixty-four amulets, and another sixty to a hundred for the fear clues and resolutions, we had not realised the extent of the undertaking. This, among others, was a significant factor in the protracted production process as archives were scoured, rights negotiations pleas made (and usually answered but occasionally and in key instances rejected), and postcard vendors scoured.

Where to find: a cavalry horse on a pontoon, a train passing the White Horse Hill, a pre-World War 1 postcard of a gondala foregrounding the abstraction of a seahorse on its prow, a Russianstyle cottage in England? Ultimately, all these and many more equally obscure were sourced, but the process was highly iterative, not least in light of the cost of licensing Imperial War Museum images. The choice of amulet and anecdote, the availability of story and fear images all impacted on one another: if one element was missing, the whole had to be reassessed.

The generosity of most collections and archives was extraordinary: above all the Bishopsgate Institute, the Pitts Rivers Museum, the Cuming Museum, the Science Museum, the Museum of Witchcraft, Memories Pictures, the Wellcome Collection itself, Memories Pictures, the London Sound Survey and Gail Durbin. Even so, the task was onerous. What their collaborative effort pointed to most excitingly, though, was the potential for reuse of 'narrative forms' like that used for Magic in Modern London in a future world of linked data, where the content slots can be filled on the fly.

Of the sixty-four amulets finally used, fewer than half had been in the original selection: this redundancy ramified through the whole process of selection. It was the result of a technical decision made early on: dynamic composition. 


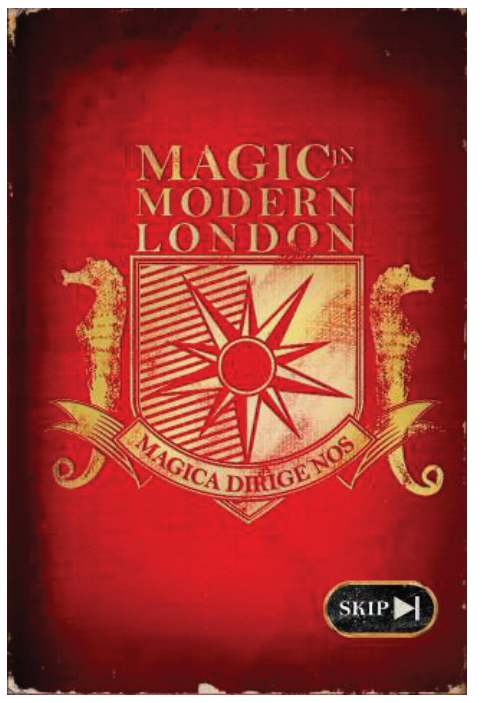

Figure 1: The app's opening screen

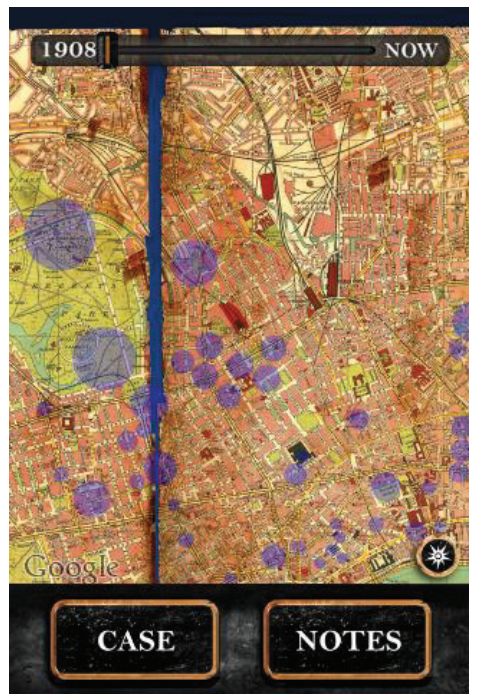

Figure 2: The overlaid 1908 map

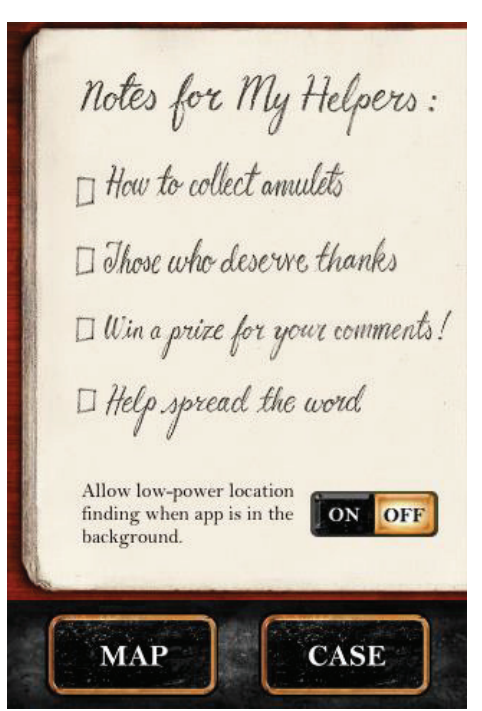

Figure 3: Notes

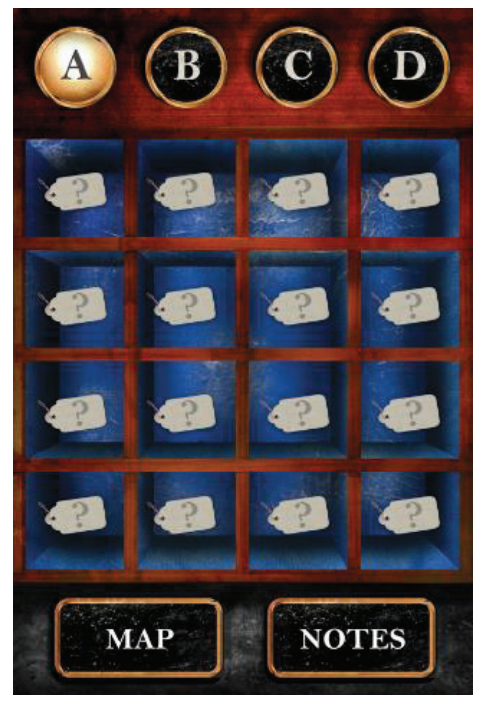

Figure 4: the collector's case

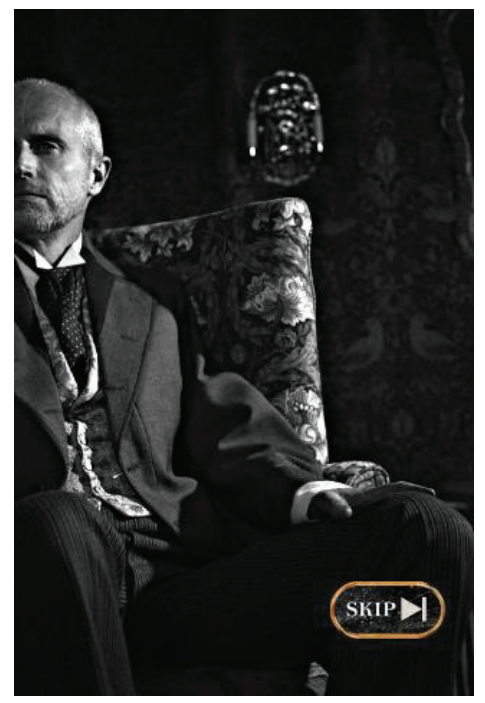

Figure 5: Stephen Hancock as the face of Lovett

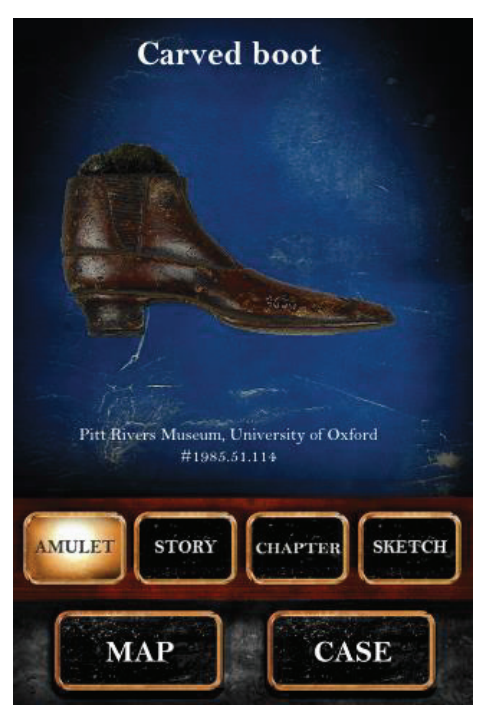

Figure 6: Aspects of an amulet 


\subsection{Dynamic composition}

The decision to apply a principle of dynamic composition for all media elements was taken by Amblr for two reasons: in order to ensure that the user encounters diversity even with only a limited (if large) set of media assets, and to explore how such an approach might work were it possible for material to be drawn in, at some later date, from the semantic web.

Such an approach, as adopted by Amblr for this and other digital projects, draws on principles of improvisionational theatre, treating the screen and the story world as a stage on which different cast members, expert in their generic roles and relationships, are asked to extemporise around a scenario. Here, the actors are the media assets, the scenario the pre-defined slots into which they will arrange themselves.

In the case of Magic in Modern London, with the various media elements required for each soundscape or audiovisual sequence selected according to certain combinatorial rules, it was possible to ensure that if five amulets are collected, the experience on each occasion will be different. However, this created significant complications for testing, both because it is not possible to test simply for individual states, and because placeholders must be used (and carefully managed) until all final assets are available.

Whilst this decision was responsible for some qualities in the app, it also slowed the development process and delayed user testing. In retrospect, it might have been considerably more efficient to prototype selected interactions in a fixed form before implementing the dynamic system.

\subsection{The user role}

Few locative projects have yet asked the user to adopt a role within the pervasive narrative, and even fewer in anything other than the most basic terms. The Museum of London's second app, Londinium, allows the user to swipe their finger across the screen as if brushing earth, to reveal archaeological remains, but the action was singular rather than part of any larger conceit. Escape from the Tower, on the other hand, does ask the user to play a role in assisting prisoners to flee, but did so in a way that was complex and clumsy.

The responses we received to tests of Magic in Modern London during development raised concerns that both the role assumed by the player and the various calls to action were not clearly understood, while the requirement for headphones had been missed by some users.
As a consequence, the design was refined in a number of ways. Good design of an animated warning on the start of screen emphasised the audio nature of the project and the need for headphones to enjoy the best experience. The addition of repeated text explanation and introduction following Lovett's opening spoken appeal to the user underlined the user role and ensured that the advice was not missed by anyone still fumbling to plug in headphones. And following the receipt of the amulet, the sequence by which the user transferred it to the collection tray was adjusted to remove any ambiguity concerning the nature of the exchange with Lovett at that point.

\subsection{The ludic and the narrative: clues and location}

Although in essence a treasure hunt for a geocached enhanced audiobook, the success of the work depended on establishing in the user a sense of coherence between the elements that comprised their experience.

In the early stages of the UX design there had been some concern around the correct balance to strike between game and story. A particular question had surrounded how challenging or otherwise the user/player would find the process of 'discovering' an amulet even when the amulet in question was consistently located at the centre of a circular 'area of enchantment visible on the screen of the phone.

In some cases, by cleverly siting the centre of an 'area' in a position where change in the urban environment during the century since the Bartholemew Map was drawn had created a more labyrinthine path, the challenge level was materially increased. More often, testing revealed that whether from a willing suspension of disbelief or sheer lack of observation, most users ignored the visual cues offered by the phone screen and directed their exploration solely according to the cues offered by the layered audio. There were no complaints that the exploration was too simple.

Less satisfactory was the Fear Clue and Resolution sequence of the experience: still the weak link in the project. The mechanic was, we believe, intrinsically effective and interesting. Upon entering an "area of enchantment" the user was challenged to consider one of the fears against which the superstitious contemporaries of Lovett might keep a protective amulet. By discovering the nearby place that had some association with either the fear, or the medical cure, or the amulet deemed protective against the fear, they would find the virtual amulet.

So diverse were the kinds of answers possible and the reasons for those answers, and so hard to 
discern in some cases was the significance of the place (somewhere marked as a toxophilia society on the Bartholemew's map for an arrowhead, or a fading painted sign for a children's hospital for fear of infant mortality) that both the clues and resolution often appeared too cryptic. A sufficient solution would have been the inclusion of a further line of specific explanation for each individual location. Unfortunately, the dynamic composition of the elements made this more complex to implement than it should have been.

Even this failing, however, did not seem to prevent the enjoyment of the app by users.

\section{CONCLUSION}

Magic in Modern London was always an experiment that set out to explore what to our knowledge was and remains entirely new ground in the use of an emerging medium. We knew it was ambitious, but we thought that the combination of stories, amulets and location based experience demanded an original treatment. The challenges as described made it a difficult process, and doing something complicated on mobile goes very much against the philosophy of 'do one thing well' for apps that we might ordinarily subscribe to. So, was it worth it?

Central to the quality of the experience is the audio: both musical and spoken. Whilst the visuals are important, it is the ability of a mobile phone to fill your ears, immersing you in its world that matters. The app may not be perfect, and with more time and budget we'd have wanted to iterate more to make it even better, but we are convinced that it is a beautiful thing, engaging, enchanting and intriguing. It allows the user to see London afresh and be transported, it is a little bit magical. Since launch, user feedback has been universally positive (with the exception of a few users who experienced bugs).

The complexity of creating powerful mobile experiences is not to be underestimated but increasingly there are seasoned practitioners to work with and good case studies such as this one on which to draw. While the creation of such an app may seem daunting, where the material is suitable we would urge cultural organisations to be bold, both in their approach and in their choice of who to work with, choosing people with a genuine creative commitment to innovation. Locative media and other digital forms of interpretation are still nascent, there is a long way to go in their development, and cautious solutions will often miss their target.

It is vital to put the experience first, to make something that will work for your audience and draw them in. This is easy to say, but not always easy to do. It is partly about using processes for development that focus on the experience, which is a major part of a new project by one of the authors, Martha Henson, called ME:CA (www.me-ca.org). This project, in conjunction with mobile experts Frankly, Green and Webb brings people from various cultural organisations together to look at what we could be doing with mobile, and why we aren't. 